\title{
Vivências de mulheres sobre a assistência recebida no processo parturitivo
}

I ${ }^{1}$ Luciano Marques Santos, ${ }^{2}$ Samantha Souza da Costa Pereira I

Resumo: Este artigo tem por objetivo compreender as vivências de puérperas sobre a atenção recebida durante o processo parturitivo em uma maternidade pública de Feira de Santana-Bahia. Estudo descritivo, exploratório e qualitativo, que respeitou a Resolução n. 196/96 do Conselho Nacional de Saúde, realizado no período de fevereiro a abril de 2010, através de entrevistas semiestruturadas com 19 puérperas. A análise de conteúdo e semiológica dos dados demonstrou que as entrevistadas vivenciaram o processo parturitivo com solidão, medo, dor, sofrimento, abandono, e tiveram seus filhos, sozinhas. Os únicos momentos de assistência foram limitados ao período expulsivo ou do pós-parto. Há necessidade de utilização de uma abordagem que estimule a participação ativa da mulher e de seu acompanhante, que priorize a presença constante do profissional junto à parturiente, preconize o suporte físico e emocional e o uso de novas tecnologias de cuidado que proporcionem o alívio da dor e o conforto da parturiente.

> Palavras-chave: enfermagem obstétrica; trabalho de parto; parto normal; saúde da mulher.
1 Enfermeiro; mestre em

Enfermagem; professor assistente (Universidade Federal do Vale do São Francisco UNIVASF). Endereço eletrônico: lucmarxenfo@yahoo.com.br

2 Enfermeira; especialista em Saúde Pública; enfermeira do Hospital Ortopédico, Feria de Santana-Bahia. Endereço eletrônico: samcosta01@yahoo. com.br 
A institucionalização do parto fez com que as mulheres deixassem de parir em seus lares, no ambiente familiar, com as parteiras, vivendo a ruptura dos hábitos de solidariedade feminina e do espaço da vida cotidiana. As práticas instituídas baseadas em normas e rotinas tornaram as mulheres passivas e impossibilitaram a presença de pessoas de seu convívio social para apoiá-las durante o trabalho de parto e parto (NAKANO et al., 2007).

À medida que os partos se deslocaram para o ambiente hospitalar, em consequência da institucionalização da medicina, outros atores envolveramse neste cenário, com o profissional médico assumindo o papel hegemônico da assistência (NUNES; MOURA, 2004). O parto então assume caráter patológico, invasivo e sem privacidade para a parturiente, que é submetida a terapêutica e decisão médica. Sendo assim, a partir do século XX, juntamente com a evolução da medicina, o parto se torna um evento hospitalar, envolvendo intervençōes médicas na fisiologia do processo parturitivo (OSAVA, 1997; CECGANO; ALMEIDA, 2004).

Desta maneira, o processo parturitivo deixa de ser um fenômeno de essência familiar, individual e fisiológico e passa a ser um momento de experiências, na maior parte das vezes negativas, perdendo assim as características de individualidade feminina e de um acontecimento natural, sendo o trabalho de parto encarado pelos trabalhadores da saúde como um evento patológico e propício para as intervenções. Apesar dos benefícios da institucionalização, a família foi desconsiderada neste processo, tornando esse momento singular uma experiência sofrida e fria, no qual a mulher é considerada como um objeto (CECGANO; ALMEIDA, 2004).

As parturientes são assistidas dentro de um ambiente hospitalar hostil, cercadas de atos de violência verbal. Por conseguinte, as rotinas hospitalares preconizam o isolamento da parturiente de seus familiares, os toques vaginais repetitivos, o uso indiscriminado de ocitocina, a dieta zero, a tricotomia vulvo-perineal, a restrição do movimento, dentre outros. As intervenções realizadas eram justificadas sob a alegação de que só o saber médico é capaz de intervir frente às complicações durante o parto, reduzindo dessa forma as taxas de mortalidade materna e neonatal (SANTOS, 2010). Assim, o uso rotineiro de condutas obstétricas a partir do século XX legitimou a tecnologização do parto e o domínio do corpo 
feminino pela obstetrícia, fortalecida pela visão estereotipada dos profissionais de que a mulher é um ser destituído de conhecimento e incapaz de entender o que está acontecendo com o próprio corpo (SANTOS; SHIMO, 2008).

Com base nestas reflexões, este estudo ${ }^{1}$ tem como objeto de investigação a vivência de puérperas sobre a atenção recebida durante o processo parturitivo. $\mathrm{O}$ interesse por este objeto surgiu durante a vivência profissional na unidade de centro obstétrico de uma maternidade pública de Feira de Santana-Bahia. $\mathrm{Na}$ admissão ocorria a separação da parturiente de seus familiares, sendo esta submetida à preparação para o parto. Além do registro de algumas informações úteis do ponto de vista clínico e obstétrico, das condições físicas da mulher e do feto, nesse momento eram prescritos procedimentos que incluíam banho, utilização de roupa privativa do hospital, punção venosa periférica, uso de ocitócitos, restrição ao leito obstétrico e jejum oral prolongado.

À parturiente era negado o direito de utilizar seus calçados durante o trabalho de parto, sendo que, na maior parte das vezes, estas mulheres ficavam descalças. A mulher não podia caminhar livremente, ou mesmo acomodar-se à vontade na cama. Seu corpo tornava-se propriedade e responsabilidade dos trabalhadores da saúde, que ditavam o comportamento adequado. Da mulher esperavase passividade ante as intervençôes. Esse ritual excluía a mulher do centro do processo de parto e lhe impunha características tecnológicas pouco relacionadas aos aspectos fisiológicos da reprodução.

Isto posto, questionou-se: como as mulheres vivenciaram a atenção recebida durante o processo parturitivo? Para tanto, este estudo teve como objetivo compreender as vivências de puérperas sobre a atenção recebida durante o processo parturitivo em uma maternidade pública de Feira de Santana-Bahia.

\section{Metodologia}

Estudo de natureza qualitativa, descritiva e exploratória, realizado na cidade de Feira de Santana-Bahia, escolhida por suas características socioeconômicas e importância geográfica, sendo o hospital público especializado na atenção à mulher no ciclo gravídico e puerperal da cidade o campo empírico desta investigação.

Os dados foram coletados no período de fevereiro a abril de 2010, após emissão de parecer favorável pelo Comitê de Ética na Pesquisa da Faculdade de Tecnologia e Ciências, campus de Salvador-Bahia, sob número 01.382-2009. 
As participantes do estudo assinaram o termo de consentimento livre e esclarecido e foram selecionadas mediante os seguintes critérios de inclusão: puérperas que estiverem internadas no alojamento conjunto para parto vaginal; puérperas com idade superior a 19 anos; puérperas de parto simples natural em vértice e puérperas com feto nativivo. $\mathrm{O}$ fechamento amostral foi definido pela saturação teórica dos dados, a partir da convergência dos achados ao objetivo proposto no estudo, participando deste estudo 19 entrevistadas. Foram excluídas as adolescentes, pois na unidade em estudo, estas parturientes têm o direito a um acompanhante, o que poderia interferir nos dados coletados, pois os profissionais de saúde poderiam mudar suas condutas diante deste sujeito.

Por razões éticas, as puérperas não foram identificadas por seus nomes, sendo assegurado o anonimato das entrevistadas, através da utilização de códigos na transcrição e divulgação da sua fala, respeitando sua integridade intelectual, social e cultural, conforme a Resolução n. 196/96, do Conselho Nacional de Saúde. Dessa forma, as participantes foram identificadas pelos seguintes códigos: E01 a E19.

Para a apreensão do material empírico, utilizou-se a técnica da entrevista na modalidade semiestruturada; para auxiliá-la, foram elaborados desenhos. Os recursos gráficos possibilitam uma ação interativa entre o sujeito e as figuras quando confrontados, sendo possível apreender como ele se sente e vive (MIRANDA et al., 2007).

A puérpera recebeu uma folha em branco, modelo A4, além de lápis coloridos. Em seguida, foi solicitado que ela realizasse desenhos que representassem sua vivência durante o processo parturitivo. Tendo feito isto, a participante foi convidada a relatar o que as imagens pretendiam significar, mediante a realização de entrevistas e utilização de um roteiro, com a seguinte questão norteadora: "conte para mim como foi o seu parto". Este momento foi gravado e depois suas respostas foram transcritas na íntegra.

Este estudo é um recorte de um trabalho de conclusão de curso de graduação em Enfermagem da Faculdade de Tecnologia e Ciências que contou com 19 desenhos de puérperas, e para elaboração deste artigo foram utilizados os registros gráficos de cinco mulheres. Desta maneira, para análise dos dados empíricos utilizou-se a Análise de Conteúdo, que corresponde a um conjunto de técnicas de análise das comunicações, que pode expressar uma análise de significados (a 
análise temática), como também uma análise dos significantes (análise léxica, análise dos procedimentos) (BARDIN, 2007).

Os desenhos foram submetidos à análise semiológica de imagem, que permite buscar uma aproximação científica de qualquer significância em uso nas diversas práticas sociais, prevendo-se a possibilidade de estudar todo projeto significante como um sistema de signos, quaisquer que sejam as diferenças existentes entre a linguagem estudada e o modelo de linguagem verbal (PENN, 2008). Assim, cada desenho foi submetido ao processo de identificação de símbolos e da decodificação, sendo a seguir os dados desta etapa relacionados aos da entrevista semiestruturada.

Foram identificadas as seguintes categorias: "A solidão durante o trabalho de parto", "As consequências da solidão durante o trabalho de parto" e "A assistência no período expulsivo/pós-parto”.

\section{Resultados e discussão}

\section{A solidão durante o trabalho de parto}

O processo parturitivo configura-se, no contexto das práticas dos profissionais de saúde, como um momento intensamente estressante para a mulher em decorrência da dor relacionada às contrações uterinas cada vez mais intensas, além de ser uma experiência notadamente estranha do ponto de vista dos atores envolvidos na cena do parto (SANTOS, 2010). Por isso, a atenção de qualidade à mulher em processo parturitivo é um direito fundamental e representa um passo indispensável para garantir que ela possa exercer a maternidade com segurança e bem-estar. A equipe de saúde deve estar preparada para acolher a parturiente, seu companheiro e demais familiares, respeitando todos os significados desse momento, com o dever de facilitar a criação de vínculos mais profundos, transmitindo-lhe confiança e tranquilidade (BRASIL, 2003; REIS; PATRÍCIO, 2005).

Entretanto, as entrevistadas deste estudo informaram que ao chegarem à maternidade não foram acolhidas pela equipe de saúde, mas foram submetidas a um ritual de preparo para o processo parturitivo. Neste, conforme fala das mulheres, a equipe padroniza a atenção, realizando rotinas sem avaliar o benefício das mesmas e as necessidades de individualidades de cada mulher. 
[...] quando eu cheguei fiquei um bocado de tempo esperando lá fora. Depois me levaram para tomar banho, me botaram no quarto (centro obstétrico), me botaram no soro e depois não foram mais me ver. (E1)

[...] eu estava vomitando, passando mal mesmo. Ela (a técnica de enfermagem) me botou em cima da maca, saiu e me deixou lá sozinha (na sala de pré-parto, parto e puerpério) $[\ldots]($ E11)

O médico pediu que me colocasse no soro, assim foi feito, fiquei no soro em torno o tempo todo. (E16)

$\mathrm{Na}$ atenção à parturiente, o acolhimento é um dos elementos fundamentais para a humanização da atenção obstétrica, pois é através deste que o trabalhador da saúde mostra-se interessado e disponível em conhecer a mulher, seus familiares e suas demandas de cuidado, amenizando assim, o medo decorrente do parto. A ausência de acolhimento, no início do contato com a unidade hospitalar, poderá contribuir com o maior desespero da mulher e seus acompanhantes, tendo em vista o tempo de espera para o atendimento médico e a possibilidade de negação do direito ao leito obstétrico.

Ainda, ao serem admitidas na unidade de centro obstétrico, as parturientes receberam um banho de aspersão e foram transferidas para a sala de parto. Neste local, foram afastadas de seus familiares, permanecendo sozinha durante todo o trabalho de parto. Estes dados também foram encontrados em outros estudos (SILVA; LOPES; DINIZ, 2004; QUEIROZ et al., 2007; RODRIGUES; SIQUEIRA, 2008; MILBRATH et al., 2009; SANTOS, 2010). Tais depoimentos revelam que os trabalhadores da saúde, no contexto da maternidade estudada, encontram-se distantes da parturiente, que em momento singular do parto carece de presença, apoio e informações sobre o que está proposto para ela dentro da assistência, mostrando que as prescrições médicas se mostram como prioridades durante a assistência.

A utilização da ocitocina intravenosa representa o afastamento dos profissionais de saúde, no que se refere ao acompanhamento da parturiente durante todo o processo, o que a faz experimentar a solidão e a sensação de abandono nas salas de parto, pois os dados apontam para o fato de que estas mulheres permaneceram sem acompanhamento da equipe do centro obstétrico, já que não foi mencionada nos seus relatos, a prestação de cuidados relacionados às demandas da parturiente e o estabelecimento de vínculos de co-responsabilidade. Por isso, mostrar- 
se próximo, preocupado e disposto a cuidar e escutar a parturiente são ações

importantes para que facilitem o processo de parto, além de fazer dele um momento de cuidado e conforto que seja único na vida de cada parturiente (FRELLO; CARRARO, 2010a).

As falas das mulheres denotam também que a utilização da ocitocina intravenosa parece substituir o cuidado dos profissionais de saúde, pois no contexto estudado parece que é utilizada como uma forma de acelerar as contrações uterinas e o parto, com vistas a diminuir o tempo de permanência da parturiente no centro obstétrico e aumentar o número de leitos disponíveis. Nota-se que, nessa unidade obstétrica, as mulheres não são acolhidas inicialmente pelos trabalhadores da saúde, já que em suas falas predominou a repetição de ritual utilizado para o preparo da mulher para uma assistência fria e despersonalizada. Por isso, pensa-se que são as relações iniciais no primeiro contato entre a equipe de trabalhadores da saúde e a parturiente algo fundamental, além de uma forma de amenizar o medo do desconhecido e da própria violência institucional ainda vigente na atenção à mulher em processo parturitivo.

Com o aumento das contraçóes uterinas, as mulheres acionaram a equipe como uma forma de amenizar a dor decorrente desse processo, já que para elas os profissionais de saúde que estavam no centro obstétrico poderiam realizar algum procedimento para aliviar seu sofrimento. No entanto, segundo essas mulheres, a equipe de saúde não deu resolutividade a suas demandas, pois os mesmos não responderam ao chamado das mesmas, conforme falas a seguir e desenho da entrevistada 4.

Eu acho que a atenção deveria ser em relação a isso, porque lhe largam lá na sala, você chama alguém e não aparece ninguém, se você demora de parir, vão apagando as luzes dos corredores todos e largam você lá na sala de parto. Eu sei que acaba sendo chato gritar bastante, mas tem que ter dor e não existe dor que você suporte calada, principalmente uma dor de parto. É terrível! (E10)

As enfermeiras não foram me ver, passavam lá no corredor e não entravam, só entraram quando eu chamei pra perguntar se eu poderia ir ao banheiro, aí elas falaram que eu poderia e saíram depois. (E12)

[...] A gente chama, chama, chama e parece que eles não escutam [...]. (E18)

Você fica chamando, não tem ninguém, e eu fiquei no desespero que eu achava até que a criança não ia sair, pedia ajuda: 'gente, fica comigo! Tá tudo bem?' eles respondiam: 'Só depende de você'! É complicado, entendeu? [...]. (E19) 


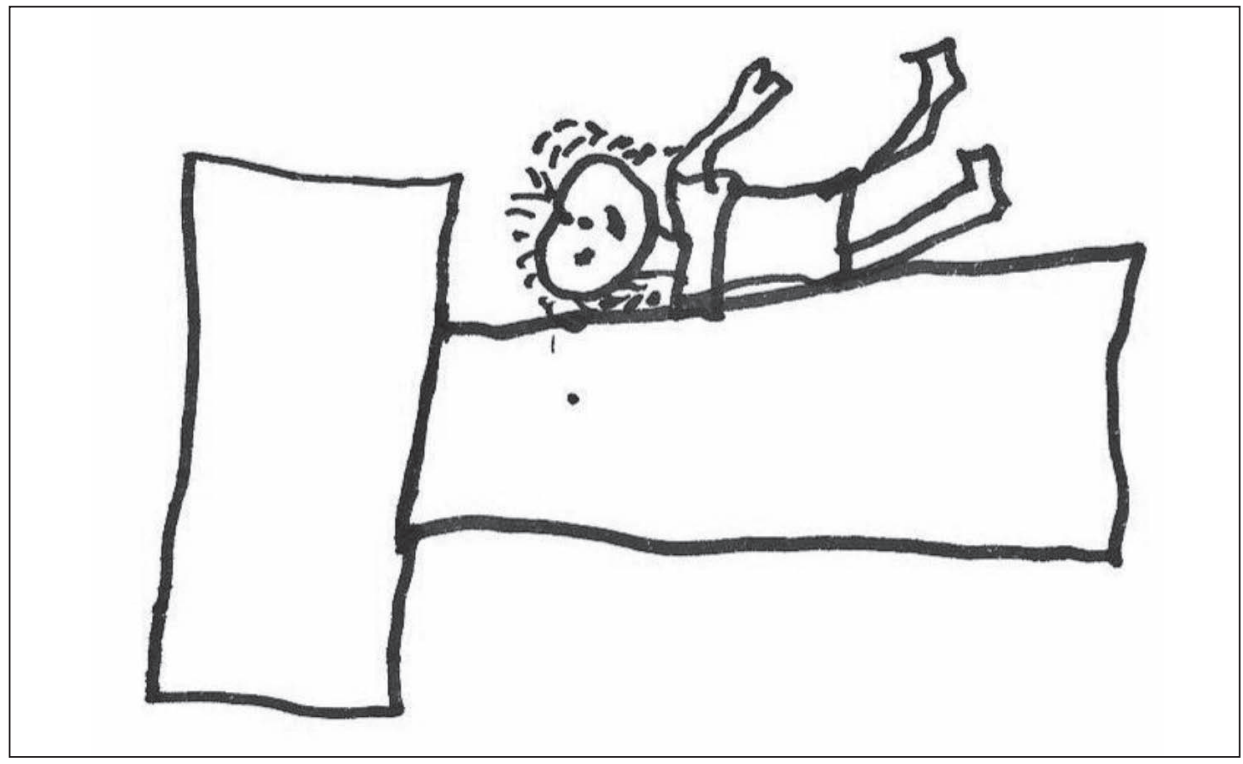

Pensa-se que as falas anteriores e a análise da figura 1 apontam para uma realidade obstétrica na qual a atenção à parturiente está limitada ao aspecto físico, representado pela execução do ritual já discutido, sendo a mulher abandonada nas salas de pré-parto, pois a ausência de respostas ao chamado da parturiente, por parte da equipe de saúde, é traduzida para estas mulheres como solidão, abandono e desespero.

A solidão do pré-parto representou para as entrevistadas como momentos de dor intensa, insegurança e insatisfação com os trabalhadores da saúde, já que, para elas, ficar sozinha durante o processo parturitivo parece assustador e ameaçador, tendo em vista a possibilidade do nascimento de seu filho ocorrer sem a presença dos trabalhadores da saúde. Estes, mesmo sabendo que as mulheres estão sozinhas, não se fazem próximos, já que estão envolvidos com outras atividades além da atenção no trabalho de parto (LAMY et al., 2000; FRELLO; CARRARO, 2010a). Por isso, essa prática vai de encontro aos princípios da humanização da atenção obstétrica, pois as mulheres vivenciaram a solidão, o medo e a tristeza diante do abandono no centro obstétrico, já que os trabalhadores da saúde não estabelecem ações contínuas de cuidado e algumas instituições hospitalares têm negado à parturiente o direito ao acompanhante durante o processo parturitivo. 
Esta realidade vivenciada pelas mulheres entrevistadas contrapõe a Lei n. 11. 108, que garante o direito ao acompanhante durante o processo do parto e nascimento, como um forma de amenizar o sofrimento e o esquecimento nas unidades de atenção obstétrica. Sendo assim, impedir a presença de um acompanhante durante o trabalho de parto e parto viola o direito da mulher como cidadã brasileira e de sua própria capacidade de autonomia, de escolha, de optar pela presença ou não de um acompanhante, de escolher a pessoa que ela deseja que esteja ao seu lado nesse momento (MILBRATH et al., 2010).

Uma das entrevistadas destacou em sua fala que um dos motivos apontados para a solidão no centro obstétrico seria o grande quantitativo de parturientes para serem atendidas, sendo esta resposta algo que a mulher não gostaria de ter escutado diante de seu sofrimento.

[...] Eu chorava e dizia: gente fica comigo um pouco, pelo amor de Deus, eu estou sozinha! [...] eles então diziam que tinha muita gente pra dar atenção. Esta é uma resposta que a gente não quer ouvir num momento desses, tão difícil. (E19)

O usuário dos serviços de saúde em geral não reclama da falta de conhecimento tecnológico no seu atendimento, mas da falta de interesse e responsabilização dos diversos serviços em torno de si e de seu problema. A postura de cuidar dos profissionais de saúde perante os usuários tem muito significado, à medida que eles se sentem valorizados e atendidos em suas necessidades (NASCIMENTO et al., 2010). Assim, nota-se um descompasso entre a prática clínica e as recomendações do Ministério da Saúde, pois esta equipe não considerou os princípios da integralidade e equidade na atenção a essas mulheres.

Durante o trabalho de parto, a maioria das mulheres almeja a presença permanente e qualificada dos profissionais, em especial quando estão vivenciando as contrações dolorosas. Entretanto, uma das entrevistadas informou que foi orientada a acionar a equipe quando estivesse no período expulsivo (ARMELLINI; LUZ, 2003).

Meu parto foi mais ou menos, porque na sala de parto as pessoas não eram muito pacientes porque elas ficam sempre reclamando, dizendo que a gente já sabia da dor e agora tava reclamando [...] quando eu chorava, não vinham no mesmo momento pra atender [...] elas (técnicas de enfermagem) achavam que eu estava fazendo escândalo, mas às vezes a pessoa está com tanta dor e aguenta ficar quieta, mas tem umas que estão com dor e não conseguem ficar quietas. [...] ela (técnica de enfermagem) me falou que era pra chamar quando eu estivesse fazendo cocô. (E18) 
Ao estabelecer comportamentos às parturientes, o profissional de saúde encontra-se distanciado do cuidar fundamental, no sentido de compreender a vivência dela, situação em que, muitas vezes, valoriza os aspectos técnicos que envolvem o parto normal, em detrimento da relação com o sujeito (SILVA; LOPES; DINIZ, 2004).

É preciso repensar a atuação dos profissionais de saúde e o modelo de atenção que valoriza a técnica em prol do relacionamento humano, para assim proporcionar condições para a inclusão da figura do acompanhante no cenário da parturição, já que negar este direito à mulher corresponde à violação de um direito fundamental de sua vida que é o de ser considerada como ser humano dotado de necessidades.

\section{As consequências da solidão durante o trabalho de parto}

As puérperas relataram o aumento da dor durante o trabalho de parto, em decorrência da infusão intravenosa do ocitócito e da solidão durante o trabalho de parto. Algumas falas evidenciaram que o soro com ocitocina foi instalado e as parturientes foram "deixadas" na sala de parto até a vigência do período expulsivo.

Eu senti muitas dores! Doeu muito depois do soro que ela colocou (técnica de enfermagem). (E3)

[...] Depois do soro eu senti muitas contrações, muitas dores. (E6)

[...] eu tenho três filhos. Acho que a dor pior foi desse agora, porque a dor das outras duas foi menor [...] uma eu tive em casa, não demorou, não levou tanto tempo, mas essa foi a pior que teve e eu estava sozinha. (E13)

[...] Fiquei no soro, senti muitas dores [...]. (E14)

[...] eu fiquei lá (na sala de parto) sozinha sentido muita dor. (E15)

A utilização da ocitocina intravenosa parece substituir a presença dos profissionais de saúde, pois a mesma é infundida com a finalidade de abreviar o trabalho de parto e acelerar o nascimento. Estes achados são complementados com a figura da entrevistada 12, na qual está representada um suporte com solução intravenosa e uma face sugestiva de dor. 


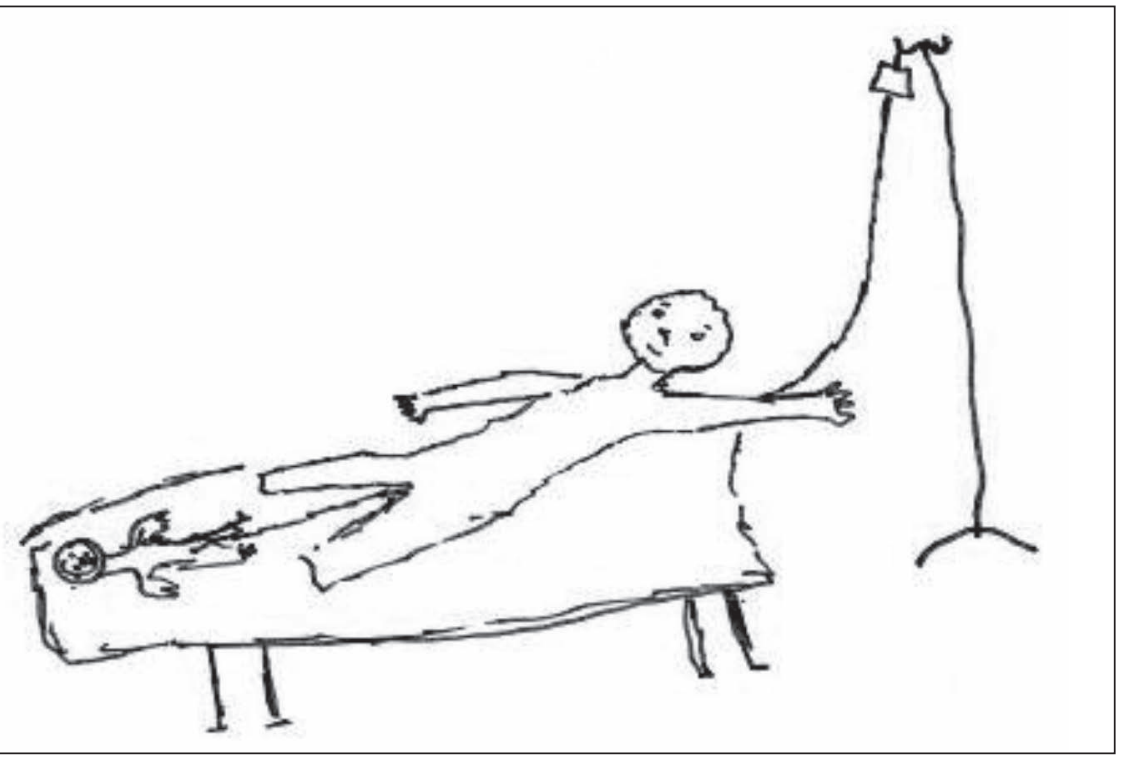

Por outro lado, uma das entrevistadas informou que, durante a sua dor, um profissional médico relatou que a resolução deste processo só dependia dela. Entretanto, esta mulher teve que vivenciar um processo muito ímpar em sua vida, já que ela não conhecia as estratégias não-farmacológicas para o alívio da dor decorrente do processo parturitivo.

[...] Foi muita dor, eu delirei e o médico simplesmente disse que dependia só de mim. Agora, depende de mim em que? Como? O que é que eu devo fazer? O que é que eu não devo? Fica difícil a gente saber. (E19)

Esta fala é complementada pelo desenho da entrevistada 12, já que a representação gráfica dos pés amputados, em conjunto com a análise da mesma, aponta para o fato de que esta mulher se sentiu limitada diante das incertezas decorrentes do trabalho de parto, sendo forçada a enfrentar sozinha as demandas decorrentes deste processo. Tal limitação reflete uma prática impessoal, fria e distanciada das recomendações ministeriais, na qual não são consideradas as queixas físicas da parturiente, tendo em vista o fato de o profissional de saúde transferir para a mulher a responsabilidade do enfrentamento do processo doloroso. 
O respeito aos sentimentos das mulheres, ao valorizar suas queixas em relação à dor durante o processo parturitivo, vivenciada de forma diferente por cada uma delas, é um passo importante de apoio da equipe, pois a experiência da parturição para a mulher é caracterizada pelo sentimento de dor forte, que a desestrutura emocionalmente (DAVIM; TORRES; DANTAS, 2008; FRELLO; CARRARO, 2010a).

As entrevistadas relataram que tiveram seus filhos, sozinhas, sem suporte dos profissionais de saúde, sendo estes achados complementados com o desenho da entrevistada 11.

Posso dizer que eu tive ela só. (E3)

[...] eu tive meu neném sozinha, ela já tinha saído, aí foi depois que eles vieram ver, quando não tinha mais graça [...]. (E11)

[...] Depois, quando meu filho nasceu eu chamei eles (a equipe da sala do centro obstétrico) e eles vieram. (E12)

Eu tive minha filha sozinha, sem ninguém de junto. Eu acho assim: que tinha que ter quando nada uma enfermeira pra na hora que a criança nascesse estar ali [...]. (E13)

[...] Quando elas vieram mesmo, tinham três pessoas pra parir de vez. Uma pariu sozinha, aí depois que vieram correndo pegar, aí depois fui eu e depois foi a outra. Aí tinha que dar atenção a todas ao mesmo tempo [...]. (E18)

Figura 3. Ilustração da entrevistada número 11

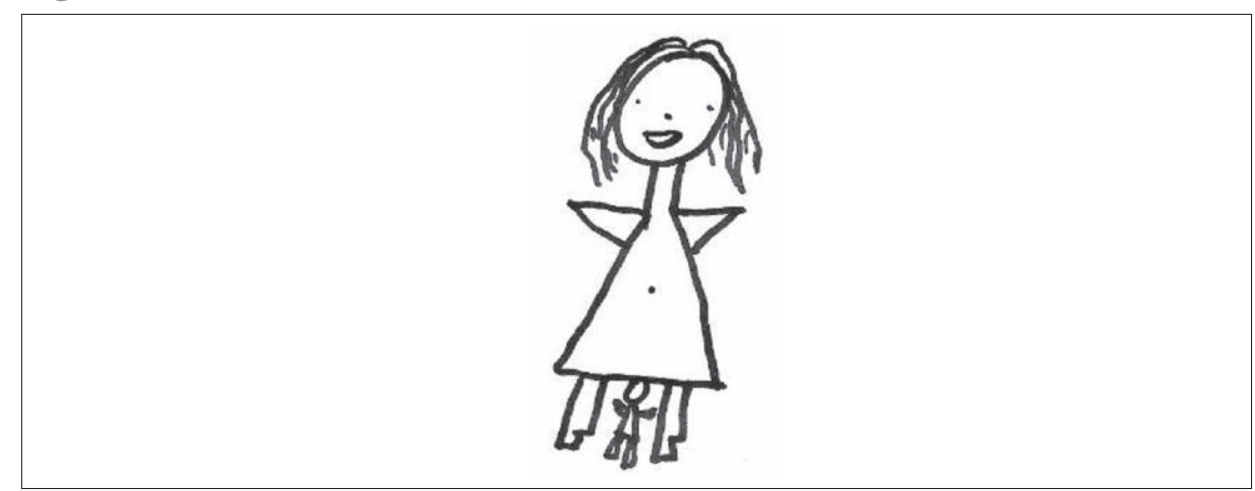

O suporte dos profissionais de saúde durante o processo do parto é confortante para as mulheres. Mostrar-se próximo, preocupado e disposto a cuidar e escutar a parturiente são ações importantes para a criação de laços de confiança e afeição, a fim de facilitar este processo, além de fazer dele um momento de cuidado e conforto (FRELLO; CARRARO, 2010 b). Desta maneira, o não- 
acompanhamento profissional durante todo o processo parturitivo representa a negação do direito de exercer a maternidade segura, já que as consequências da solidão na sala de parto poderão prejudicar o contato inicial entre mãe e filho, em decorrência do desgaste emocional demandado pelo processo parturitivo sofrido.

Outra consequência relatada pelas entrevistadas foi o desespero durante a expulsão do concepto e a ocorrência de lacerações na região vulvoperineal, o que foi representado no desenho da entrevistada 13.

Quando ela tinha acabado de dar as costas, foi botar a luva, o menino já estava saindo, aí ela me mandou segurar, só que eu não estava aguentando mais de tanta dor e empurrei pra fora. Ela colocou a luva correndo e ainda deu tempo de pegar mesmo assim [...] depois teve que costurar, pois lacerou um pouco. (E2)

[...] Eu tive um corte enorme [...]. (E3)

[...] Levei um corte enorme e, se eu não me engano, tive uns vinte pontos [...]. (E14)

Eu sofri com o corte bem grande [...] e a médica falou que levou mais de trinta pontos [...]. (E6)

[...] ela já tinha saído, aí foi depois que eles vieram ver, quando não tinha mais graça

[...] Não recebi nenhum corte, ainda bem, só ponto mesmo. (E9)

Figurra 4. Ilustração da entrevistada número 13
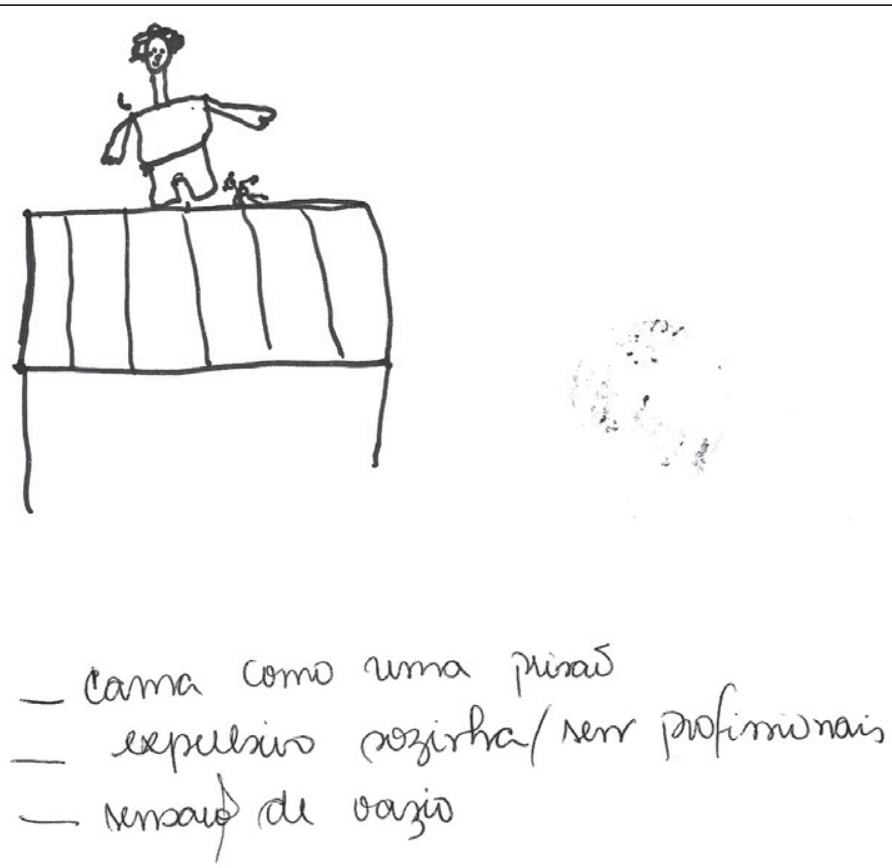
A infusão intravenosa de ocitocina, que é utilizada para acelerar o parto, com aumento das contrações e da pressão intra-uterina no período expulsivo do parto, pode acarretar o desprendimento cefálico abrupto e a laceração perineal (SCARABOTTO; RIESCO, 2006). Conforme as falas das entrevistadas, é fundamental o acompanhamento da equipe de saúde durante todo o processo, como forma de garantir a segurança e o bem-estar materno, pois para ela a presença destes profissionais somente no momento da ocorrência do nascimento não foi tão importante quanto a vigilância constante.

As instituiçõos públicas de saúde também devem visar à qualidade da assistência, pois todas as pessoas têm direito ao atendimento qualificado e digno. Devem, para isso, investir nas condições necessárias para a prestação da assistência com qualidade e instituir uma cultura de busca incansável por esta meta a todos os profissionais da instituição, a fim de atender adequadamente às necessidades e expectativas provenientes das clientes (MOURA; COSTA; TEIXEIRA, 2010). Por isso, esforços são necessários a fim de proporcionar um ambiente agradável, com recursos para o alívio da dor e profissionais aptos para oferecer às parturientes opçóes de conforto, durante o processo de parto (FRELLO; CARRARO, 2010b).

Entretanto, implementar na prática clínica medidas para o alívio da dor no processo parturitivo parece ser um desafio a ser superado pelos profissionais de saúde, pois a dificuldade parte da ausência de conhecimento sobre a ação e benefícios das mesmas. Por outro lado, é necessário o acompanhamento constante da evolução da mulher, para assim poder escolher com segurança a estratégia mais efetiva e considerar a opinião da parturiente.

\section{A assistência no período expulsivo/pós-parto}

Para as entrevistadas, a atenção durante o processo parturitivo se resumiu aos cuidados prestados pela equipe durante o nascimento. Elas consideraram este momento como bom, devido ao fato de os profissionais atuantes terem sido rápidos no apoio à expulsão do concepto, aliviando sobremaneira a dor das contrações uterinas, o que foi confirmado nas falas a seguir e na figura 5.

[...] Foi bem rápido, o atendimento foi legal, só demorou um pouquinho porque o médico estava em outro parto, mas ele foi legal, foi rápido, graças a Deus. (E3) 
[...] depois que a menina nasceu foi que eu gritei a enfermeira, aí a enfermeira veio, pegou a menina, depois foi que o médico veio e tirou a placenta [...]. (E13)

[...] foi rapidinho, pois tiraram o neném, não me deram corte nem pontos. Ele (o médico) tirou o bebê, depois a placenta e depois me trouxeram pra aqui [...]. (E17)

Figura 5. Ilustração da entrevistada número 5

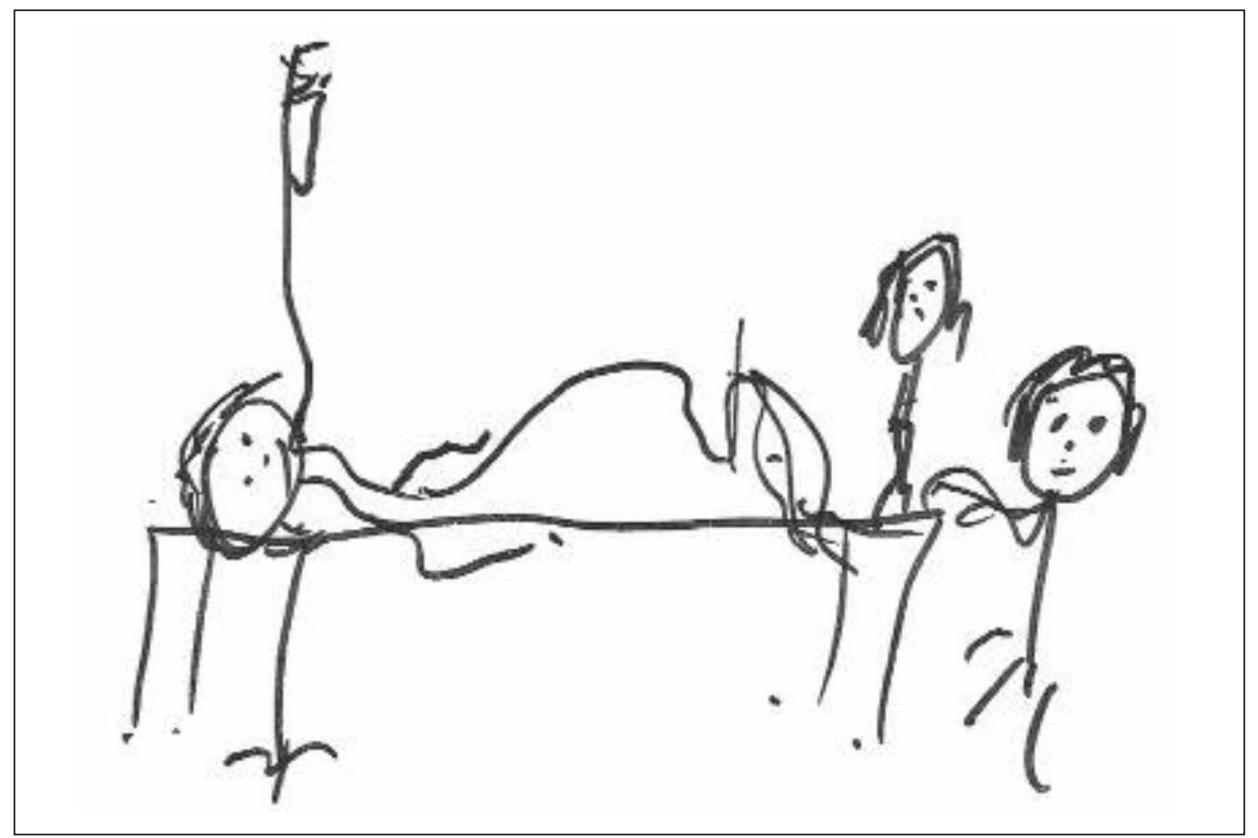

As entrevistadas destacam a figura do médico como o agente responsável pelo seu alívio, mas a atenção oferecida por este profissional se deu do ponto de vista técnico, já que atuou como coadjuvante na finalização do parto ou delivramento placentário. Ainda, a participação da equipe de enfermagem neste cenário se faz mediante recepção do recém-nascido para a prestação de cuidados voltados para a adaptação extra-uterina, conforme análise das falas das entrevistadas e da figura 6 .

No processo de trabalho em saúde hospitalar, o agente condutor é a figura do médico, sendo a parturiente objeto de sua assistência. As prescrições rotineiras, não individualizadas, constituem o processo de trabalho de assistência ao parto. Tais situaçôes denotam que uma das finalidades deste processo de trabalho é mais tratar o parto para atender às necessidades do profissional do que as da 
parturiente (SODRÉ; LACERDA, 2007). Desta forma, os dados apresentados denotam uma atenção voltada para a resolução do processo parturitivo, já que a mulher não é considerada no contexto da parturição como um todo, pois os dados parecem demonstrar uma realidade local pautada na transferência de responsabilização pela condução do parto pelas próprias mulheres, do ponto de vista da resolução das demandas oriundas deste processo.

Figura 6. Ilustração da entrevistada número 14

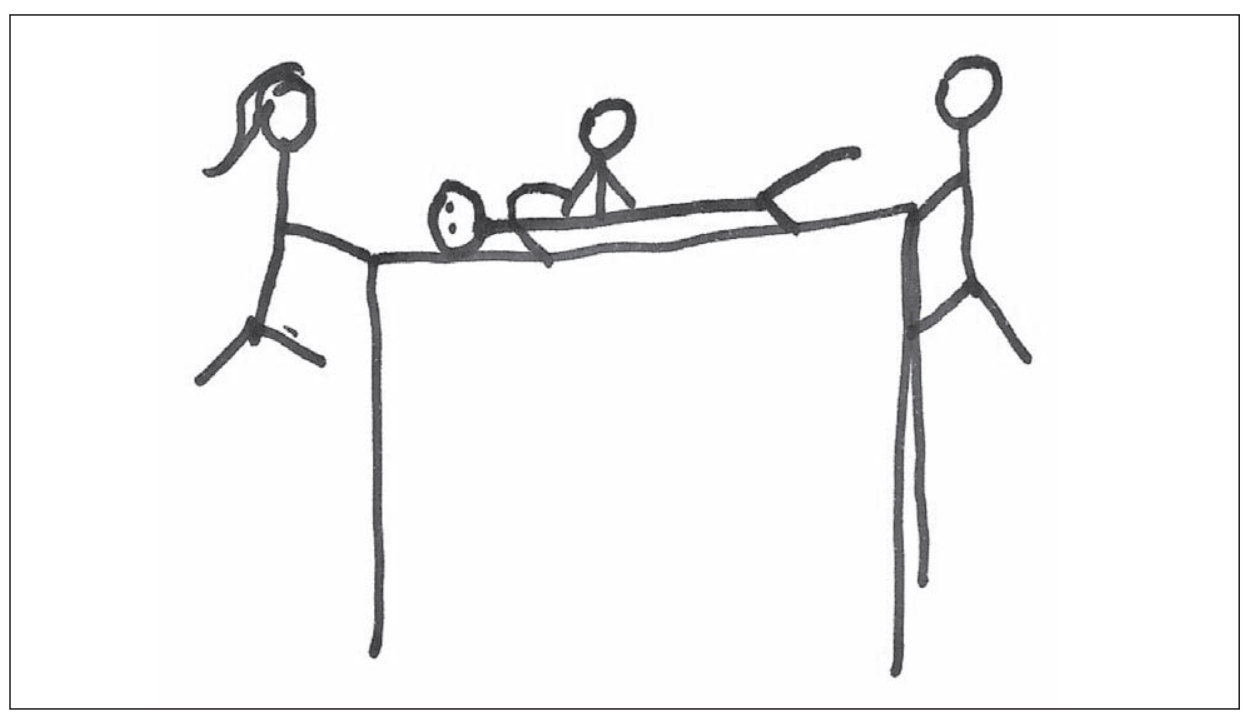

Mediante contato com os profissionais de saúde no período expulsivo ou no pós-parto, as entrevistadas relataram ter gostado da assistência recebida, pois os profissionais que auxiliaram neste momento foram cordiais e possibilitaram espaço para o estabelecimento de comunicação.

[...] Conversei com ele (o médico) [...] ele fez meu parto bem, graças a Deus [...]. (E4)

[...] o tratamento do médico que fez meu parto foi ótimo porque ele teve muita paciência comigo. (E7)

[...] O médico chegou depois, "cortou o umbigo", tirou a placenta, perguntou se estava tudo bem, eu disse que estava [...]. (E13)

Eu recebi um corte e achei esse momento bom, porque ela (referindo-se à médica) passou esse momento conversando comigo, deu anestesia, não doeu nada, eu achei maravilhoso. (E5) 
A escuta profissional durante a hospitalização obstétrica foi valorizada pelas puérperas, pois a simples presença deste agente é considerada significativa para as mesmas, partindo do pressuposto de que a resolução de suas necessidades decorre deste indicador inicial.

A valorização da escuta e do diálogo nas relações interpessoais com a equipe de enfermagem fica evidente a partir do respeito, escuta, atenção e atendimento das necessidades mínimas que a equipe pode oferecer à clientela. No entanto, a satisfação das puérperas em relação ao atendimento na maternidade reflete a interação com os profissionais e não a assistência em si, pois desconhecem seus direitos e declararam-se satisfeitas simplesmente por conseguirem atendimento (MOURA; COSTA; TEIXEIRA, 2010).

Mesmo recebendo todo tipo de ajuda, esta não se qualifica como tal quando a mulher não encontra no profissional uma pessoa com disponibilidade de vêla como pessoa e que a trate com atenção, carinho e preocupação. $\mathrm{Na}$ ausência desses elementos, as mulheres se sentem fragilizadas, assustadas e perdidas (SOARES; SILVA, 2003). Por isso a entrevistada 14 relatou a assistência no período expulsivo através da manobra de Kristeller, caracterizada pela pressão no fundo do útero durante o trabalho de parto, como uma maneira de acelerar a expulsão do concepto. Para esta entrevistada, esta foi uma conduta muito dolorosa e grosseira, pois a mesma não recebeu nenhuma informação que justificasse sua realização.

[...] a única coisa que eu tenho que falar é que meu parto foi um pouco forçado, que a mulher (a médica) fazia muita força, eu não tinha muita força e forçaram muito minha barriga e o bebê nasceu com uma secreçãozinha na cabeça [...] e até hoje sinto minha barriga doer da força que fizeram. (E14)

A manobra de Kristeller inibe a segurança e o bem-estar da parturiente, sendo desaconselhada na prática clínica diária pelo Ministério da Saúde (REIS; PATRÍCIO, 2005). Sendo assim, a utilização dessa manobra reflete a ausência de suporte durante o processo parturitivo, pois nestas condições a mulher chega ao período expulsivo desgastada, mediante esforços despendidos antes do nascimento. Para tanto, os profissionais de saúde empregam este recurso para acelerar o nascimento, como forma de reduzir seu contato com a fisiologia do nascimento, não considerando a situação da parturiente. 


\section{Considerações finais}

Compreender as vivências de puérperas sobre a atenção recebida durante o processo parturitivo nos permitiu desvelar que elas permaneceram sozinhas na sala de parto, sendo acompanhadas apenas no período expulsivo ou no pós-parto pela equipe de saúde.

As vivências descritas e representadas pelos desenhos denotam a falta de humanização da assistência prestada pela equipe de saúde e a ausência do vínculo entre parturientes e profissionais. Estas características se traduzem, para as puérperas, como uma assistência fria e indiferente, distando da atenção que elas idealizam receber na vigência do parto.

A sala de parto foi retratada pela maior parte das entrevistadas como um ambiente de dor intensa, aflição, solidão e abandono. Esta imagem contraria a ideia que se concebe sobre o evento do nascimento, cogitando-se este episódio como um momento de felicidade, realização, celebração da vida.

No entanto, a atenção humanizada será factível apenas quando os diversos atores envolvidos na parturição se dispuserem a repensar sua prática diária, redimensionando-a, quando necessário se fizer. Isso implicará, inevitavelmente, a reorganização do serviço e o abandono de técnicas padronizadas e atitudes estereotipadas que priorizam a rotina, a tecnologia e a comodidade da equipe em detrimento do bem-estar da mulher. Sendo assim, haverá a possibilidade de remover a mulher da condição de objeto da parturição, cuja voz não se faz ouvir, devolvendo-lhe a qualidade de protagonista e a capacidade de decidir sobre questôes relacionadas ao seu parto.

Pensa-se ser necessária para a melhoria da prática clínica desses trabalhadores da saúde uma nova abordagem que estimule a participação ativa da mulher e de seu acompanhante, que priorize a presença constante do profissional junto à parturiente, preconize o suporte físico e emocional e o uso de novas tecnologias de cuidado que proporcionem o alívio da dor e o conforto da parturiente.

Além disso, este estudo poderá contribuir para que a equipe de saúde possa avaliar sua prática clínica e utilizar estratégias para a humanização do cuidado à mulher em processo parturitivo. Acredita-se, também, que os dados empíricos resultantes deste trabalho, somados ao déficit de conhecimento concernente ao seu objeto, poderão estimular a realização de novas investigações. ${ }^{2}$ 
ARMELLINI, C.J.; LUZ, A.M.H. Acolhimento: a percepção das mulheres na trajetória da parturição. Revista Gaúcha de Enfermagem, v.24, n.3, p.305-15, dez 2003.

BARDIN, L. Análise de conteúdo. Lisboa: Edições 70, 2007. 222p.

BRASIL. Ministério da Saúde. Secretaria de políticas de Saúde. Área Técnica de Saúde da Mulher. Parto, aborto e puérperio: assistência humanizada à mulher. Brasília: Ministério da Saúde, 2003. 199p.

CECAGNO, S.; ALMEIDA, F.D.O. Parto domiciliar assistido por parteiras em meados do século XX numa ótica cultural. Texto e Contexto em Enfermagem, v.13, n.3, p.409-13, Jul/Set 2004.

DAVIM, R.M.B.; TORRES, G.V.; DANTAS, J.C. Representação de parturientes acerca da dor de parto. Revista Eletrônica de Enfermagem, v. 10, n. 1, p. 100-109, 2008. Disponível em: <http://www.fen.ufg.br/revista/v10/n1/v10n1a09.htm>. Acesso em: 12 jan. 2010.

FRELLO, A.T.; CARRARO, T.E. Componentes do cuidado de enfermagem no processo de parto. Revista Eletrônica de Enfermagem, v.12, n.4, p.660-8, 2010a. Disponível em: <http:// www.fen.ufg.br/revista/v12/n4/v12n4a10.htm>. Acesso em: 12 mai. 2010.

FRELLO, A.T.; CARRARO, T.E. Conforto no processo de parto sob a perspectiva das puérperas. Revista de Enfermagem da UERJ, v. 18, n. 3, p.441-5, Jul/Set 2010b.

LAMY, Z.C. et al. O olhar das mulheres: vivendo a gravidez e o parto. In: ALVES, M.T.S.; SILVA, A.A.M. (Orgs). Avaliação de qualidade de maternidades: assistência à mulher e ao seu recém-nascido no Sistema Único de Saúde. São Luís: Gráfica Universitária da UFMA, 2000. p. 56-63.

MILBRATH, V.M. et al. Vivências maternas no processo de parturição. Escola Anna Nery Revista de Enfermagem, v.14, n.2, p.462-467, Abr/Mar 2010.

MIRANDA, F.A.N. et. al. Figuras e significados: recursos gráficos na pesquisa de representaçôes sociais. Revista Eletrônica de Enfermagem, v.9, n.2, p.526-536, 2007. Disponível em: http:/www.fen.ufg.br/revista/v9/n2/v9n2a19.htm. Acesso em: 07 jun. 2009.

MOURA, M.A.V.; COSTA, G.R.M.; TEIXEIRA, C.S. Momentos de verdade da assistência de enfermagem à puérpera: um enfoque na qualidade. Revista de Enfermagem da UERJ, v.18, n.4, p.429-34, Jul/Set 2010.

NAKANO, A.M.S. et al. Support during the labor and delivery processes: viewpoint of companions of women giving birth. Acta Paulista de Enfermagem, v.20, n.2. p.131-137, Apr./June 2007.

NASCIMENTO, N.M. et al. Tecnologias não invasivas de cuidado no parto realizadas por enfermeiras: a percepção de mulheres. Escola Anna Nery Revista de Enfermagem, v.14, n.3, p.456-461, Ju/Set 2010. 
NUNES, I.M.; MOURA, M.A.V. A atenção ao parto como espaço de poder. Acta Paulista de Enfermagem, v.17, n.3, p.340-6, Jul/Set. 2004.

OSAVA, R.H. Assistência ao parto no Brasil: o lugar dos não-médicos. 1997. 129p. Tese (Doutorado em Saúde Pública) - Faculdade de Saúde Pública, Universidade de São Paulo, São Paulo, 1997.

PENN, G. Análise Semiótica de imagens paradas. In: BAUER, M.W.; GASKELL, G. Pesquisa qualitativa com texto, imagem e som. Um manual prático. 7. ed. Petrópolis: Vozes; 2008.

QUEIROZ, M.V.O. et al. Indicadores da qualidade da assistência ao nascimento baseado na satisfação de puéperas.Texto e Contexto em Enfermagem, v.16, n.3, p.479-87, 2007.

RODRIGUES, A.V.; SIQUEIRA, A.A.F. Sobre as dores e temores do parto: dimensões de uma escuta. Revista Brasileira de Saúde Materno-Infantil, v.8, n.2, p.179-186, Abr/Jun 2008. REIS, A.E.; PATRÍCIO, Z.M. Aplicação das ações preconizadas pelo Ministério da Saúde para o parto humanizado em um hospital de Santa Catarina. Ciência e Saúde Coletiva, v.10, supl., p.221-230, Set/Dez 2005.

SANTOS, L.M. Análise da atenção à saúde da mulher no ciclo gravídico e puerperal. 2010. 277p. Dissertação (Mestrado em Enfermagem) - Escola de Enfermagem, Universidade Federal da Bahia, Salvador, 2010.

SANTOS, J.O.; SHIMO, A.K.K. Pratica rotineira da Episiotomia: refletindo a desigualdade de poder entre profissionais de saúde e mulheres. Escola Anna Nery Revista de Enfermagem, v.12, n.4, p.645-50, Dez. 2008.

SILVA, J.M.O.; LOPES, R.L.M; DINIZ, N.M.F. Vivência do parto normal em adolescentes. Revista Brasileira de Enfermagem, v.57, n.5, p.596-600, Set/Out 2004.

SOARES, A.V.N.; SILVA, I.A.S. Representações de puérperas sobre o sistema alojamento conjunto: do abandono ao acolhimento. Revista da Escola de Enfermagem da USP, v.37, n.2, p.72-80, 2003.

SCARABOTTO, L.B.; RIESCO, M.L.G. Fatores relacionados ao trauma perineal no parto em nulíparas. Revista da Escola de Enfermagem da USP, v.40, n.3, p.389-395, 2006.

SODRÉ, T.M.; LACERDA, R.A. O processo de trabalho na assistência ao parto em Londrina-PR. Revista da Escola de Enfermagem da USP, v.41, n.1, p.82-9, 2007.

\section{Notas}

${ }^{1}$ Artigo elaborado a partir do trabalho de conclusão de curso intitulado "Percepção da puérpera sobre a atenção no processo parturitivo em uma maternidade pública do interior da Bahia" e apresentado ao colegiado de Enfermagem da Faculdade de Tecnologia e Ciências, Feira de Santana-Bahia, Brasil, em 2010. Este estudo não recebeu financiamento e não há nenhum conflito de interesse envolvido.

${ }^{2}$ L.M. dos Santos e S.S. da Costa participaram da concepção e desenho, análise e interpretação, pesquisa bibliográfica, redação e aprovação final do artigo; L.M. dos Santos realizou a revisão crítica do texto. 


\section{Abstract}

Experiences of women on the care received during the parturition process

This paper aims to understand the mothers' experiences on the care received during the birth process in a public maternity in Feira de Santana, state of Bahia, Brazil. This is a qualitative descriptive exploratory study that complied with the Resolution 196/96 of the National Health Council and was conducted from February to April 2010, through semi-structured interviews with 19 puerperas. The Content Analysis of data showed that the respondents had experienced the birth process with loneliness, fear, pain, suffering and abandonment. The assistance occurred only during the expulsive period or in the postpartum. It is needed to use an approach that encourages women and their companions' participation, which prioritizes the constant presence of professionals with the parturient, proposes the physical and emotional support and the use of new care technologies that provide relief pain and the parturient's comfort.

Key words: obstetrical nursing; labor, obstetric; natural childbirth; women's health. 